\title{
Effect of Silicon, Manganese and Heating Rate on the Ferrite Recrystallization Kinetics
}

\author{
Vitesh SHAH, ${ }^{1)}$ Monika KRUGLA, ${ }^{2,3) *}$ Sven Erik OFFERMAN, ${ }^{2)}$ Jilt SIETSMA ${ }^{2)}$ and David Neal HANLON ${ }^{3)}$ \\ 1) Department of Materials Science and Engineering, Delft University of Technology. Now at Max-Planck-Institut fur \\ Eisenforschung GmbH, Max-Planck-Strasse 1, Dusseldorf, 40237 Germany. \\ 2) Department of Materials Science and Engineering, Delft University of Technology, Mekelweg 2, 2628 CD Delft, \\ Netherlands. \\ 3) Tata Steel Research and Development, 1970 CA IJmuiden, Netherlands.
}

(Received on August 2, 2019; accepted on November 25, 2019; J-STAGE Advance published date: February 13, 2020)

\begin{abstract}
This study presents the effects of silicon (Si) and manganese $(\mathrm{Mn})$ concentration and of heating rate on the ferrite recrystallization kinetics in seven model alloys with different $\mathrm{Si}$ and $\mathrm{Mn}$ concentrations, which are of relevance for the development of Advanced High Strength Steels (AHSS). The recrystallization kinetics were studied with in-situ 2D X-ray Diffraction (2D-XRD) and ex-situ microstructure observations using Scanning Electron Microscopy (SEM). The experimentally observed differences in the recrystallization start temperature $\left(T_{s}\right)$, dependent on the $\mathrm{Si}$ and $\mathrm{Mn}$ concentrations and the heating rate, can be described by combining the non-isothermal JMAK-model with a modified version of Cahn's solute drag model. The modified Cahn model takes into account - in an approximate manner - that the interaction energy of the solute atoms with the grain boundary depends on the Si and Mn concentrations in the boundary and the Wagner interaction parameters. The collective contribution of the Si and $\mathrm{Mn}$ atoms to the increase in the $T_{s}$ with respect to the reference alloy (without $\mathrm{Si}$ and with very little $\mathrm{Mn}$ ) is higher than would be expected from the simple addition of the effects of the Si and $\mathrm{Mn}$ concentrations alone. This means that the interaction between $\mathrm{Si}$ and $\mathrm{Mn}$ atoms leads to an additional increase in $T_{\mathrm{s}}$, i.e. a coupled solute drag effect. For the later stages of recrystallization, we have studied the change in the number density and the growth rates of the recrystallizing grains using SEM. The observations show non-random nucleation, early impingement of the grains in the normal-direction and non-constant growth rates of recrystallizing grains.
\end{abstract}

KEY WORDS: ferrite recrystallization; recrystallization start temperature; coupled solute drag; manganese; silicon.

\section{Introduction}

Environmental concerns and the need for better fuel efficiencies have led to an increasing demand for lighter cars. ${ }^{1)}$ In addition, electric cars that are lighter may benefit from a larger driving range. Stronger steels enable the use of lighter gauges and ultimately a reduction of the weight of the Body In White (BIW) without compromising on safety. ${ }^{1,2)}$ Many modern high strength steels contain multiple phases thereby providing an attractive combination of strength and formability. ${ }^{1)}$ During the production process, cold-rolled steel may be heated and soaked at inter-critical temperatures before being subjected to different types of cooling profile designed to obtain the desired multi-phase microstructures. In such a production cycle, deformed ferrite recrystallizes during the heating stage. ${ }^{3)}$ The resulting ferrite grain structure and texture play a significant role in determining the properties of the final product. Additionally, the progress of ferrite recrystallization may affect the

\footnotetext{
* Corresponding author: E-mail: Monika.Krugla@tatasteeleurope.com DOI: https://doi.org/10.2355/isijinternational.ISIJINT-2019-475
}

formation, distribution and the amount of austenite formed at elevated temperatures. ${ }^{4,5}$ Therefore, ferrite recrystallization during heating plays a significant role in determining the final microstructure of the steel at room temperature and in turn the mechanical properties of the steel.

The basic mechanisms involved in recrystallization are mostly well understood and researched. ${ }^{6-8)}$ However, the effect of the interplay of multiple alloying elements on the recrystallization kinetics remains difficult to predict. The binary iron alloys have been first investigated by Abrahamson ${ }^{9)}$ and Antonione. ${ }^{10)}$ The conclusion reached by both is that even small additions of substitutional elements lead to an increase in recrystallization start temperature $\left(T_{\mathrm{s}}\right)$. Later studies used ternary alloys of $\mathrm{Fe}-\mathrm{C}-\mathrm{X}$, i.e. iron $(\mathrm{Fe})$, carbon (C) and a substitutional alloying element indicated by $\mathrm{X}$ (e.g. silicon or manganese), for examining the austenite recrystallization kinetics. ${ }^{11,12)}$ An exemplary study by Medina et al. $^{11)}$ shows that additions of silicon (Si), manganese $(\mathrm{Mn})$ and molybdenum $(\mathrm{Mo})$ increase the activation energy for austenite recrystallization, which they attribute to the solute drag effect. Furthermore, they show that this effect is dependent on the concentrations of these elements. 
Similarly, it is shown that Mn retards recrystallization of ferrite. ${ }^{4)}$ In contrast, Drumond et al. ${ }^{13)}$ show that $\mathrm{Si}$ accelerates the ferrite recrystallization.

The binary and ternary alloys contain fewer alloying elements when compared to commercial steels. Studies published in recent years describe the recrystallization kinetics in materials such as Dual Phase (DP), Complex Phase (CP) and Transformation Induced Plasticity (TRIP) steels. ${ }^{2,5,14)}$ However, because these steels are complex with many alloying additions, separating the effects of individual alloying elements and identifying the interactions between alloying elements is difficult. Moreover, the studies of ferrite recrystallization have been mostly performed for isothermal heat treatments, which is scientifically very relevant, but which generally does not represent industrial conditions that involve continuous heating. During continuous heating austenite formation may take place in conjunction with recrystallization. $^{3-5)}$ The influence of ferrite recrystallization on austenite formation has been studied widely as well. ${ }^{3,15,16)}$ However, the simultaneous occurrence of recrystallization and austenite formation makes it more difficult to study the effects of solutes on the recrystallization. For example, a study shows that austenite formation slows down ferrite recrystallization, which makes it more difficult to determine the influence of alloying elements on the recrystallization kinetics. ${ }^{3)}$

Alloy segregation present in commercial materials presents further complication. Most strip steels have micro-chemically banded alloying element profiles. ${ }^{17,18)}$ Consequently, the microstructure can consist of alternating bands of ferrite and second phases with different concentrations of elements. ${ }^{18)}$ This could possibly cause local variations in nucleation and growth of recrystallized grains. In addition, the combined effects of Si and $\mathrm{Mn}$ seem to be even more relevant due to their co-segregation not only in bands but also at ferrite grain boundaries. ${ }^{19,20)}$

As stated above, substitutional alloying elements change the kinetics of recrystallization mainly through solute drag effects. Some analytical models have been developed to describe the solute drag effect in binary systems. ${ }^{21,22)}$ Recently, solute drag in multi-component systems has been investigated. ${ }^{19,20,23,24)}$ These solute drag models have mostly been applied to model the solute drag effect on ferrite grain growth during phase transformation. ${ }^{25)}$ Some ternary systems such as $\mathrm{Fe}-\mathrm{C}-\mathrm{Mn}, \mathrm{Fe}-\mathrm{C}-\mathrm{Si}, \mathrm{Fe}-\mathrm{Mn}-\mathrm{N}$ have been studied with respect to their segregation at the ferrite grain boundaries, mainly during phase transformation. ${ }^{25-27)}$ In the context of new differentiated product, the $\mathrm{Fe}-\mathrm{C}-\mathrm{Mn}-\mathrm{Si}$ system is very relevant for the steel industry and has already been studied for ferrite grain growt ${ }^{24)}$ and phase transformation. ${ }^{20)}$ However, the complexity of the system is such that the interaction parameters, diffusion coefficients and segregation parameters need to be considered as fitting parameters for the calculations. ${ }^{20,24)}$ There have been no detailed studies on the combined effect of $\mathrm{Si}$ and $\mathrm{Mn}$ on the ferrite recrystallization kinetics. Since both alloying elements are increasingly used in commercial strip steels, it seems important to study the $\mathrm{Fe}-\mathrm{C}-\mathrm{Mn}-\mathrm{Si}$ system and to determine the influences of $\mathrm{Si}$ and $\mathrm{Mn}$ concentrations and of heating rate on the ferrite recrystallization process.

\section{Methodology}

\subsection{Materials \& Heat-treatments}

In order to study the effects of $\mathrm{Mn}$ and $\mathrm{Si}$ concentrations on the ferrite recrystallization kinetics, model alloys of $\mathrm{Fe}-\mathrm{C}-$ $\mathrm{Mn}-\mathrm{Si}$ were used. Two levels of $\mathrm{Mn}$ were chosen, i.e. 0.1 and $2.0 \mathrm{wt} . \%$, while the $\mathrm{Si}$ content varies from 0.06 to $1.5 \mathrm{wt} . \%$ in the different alloys (see Table 1). A carbon concentration of $0.2 \mathrm{wt} \%$ was maintained for all the alloys. The impurities (e.g. S, Cr, Al) are kept to minimum level. All the alloys are cast as $23 \mathrm{~kg}$ ingots with dimensions of $100 \times 100 \times 230$ $\mathrm{mm}^{3}$. Afterwards, the ingots were reheated to $1250^{\circ} \mathrm{C}$ and subjected to rough rolling to $40 \mathrm{~mm}$. Roughed blocks were then reheated to $1230^{\circ} \mathrm{C}$ and hot rolled in 5 passes to a thickness of $4 \mathrm{~mm}$. The hot rolled strips where then cold rolled to a $75 \%$ reduction to a final thickness of $1 \mathrm{~mm}$. The hot rolled microstructures are shown in the Fig. 1. Obviously, there is a difference in pearlite content as well as banding between alloys with low- and high Mn (Table 1). The work of Tanaka et al. ${ }^{28)}$ suggests that even with significantly different pearlite contents and different distribution patterns of pearlite, the dislocation densities in the ferrite regions are in a similar range of magnitudes for different microstructures upon cold rolling to higher reductions. This allows us to assume that even in
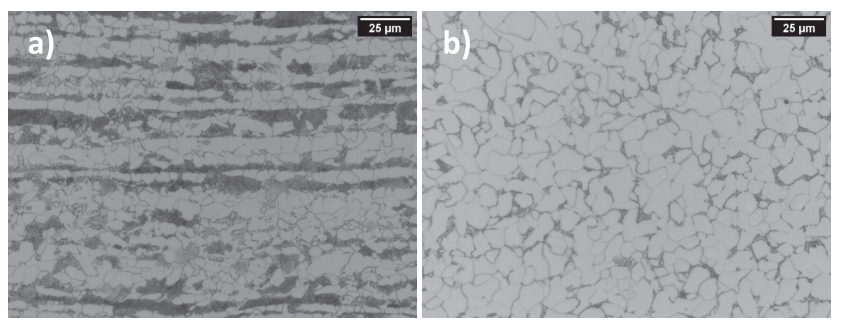

Fig. 1. Micrographs of the hot-rolled $0.4 \mathrm{Si} 2 \mathrm{Mn}$ (a) and $0.4 \mathrm{Si} 0.1 \mathrm{Mn}(\mathrm{b})$ alloys representing the differences between alloys with high $(2.0 \mathrm{wt} \%)$ and low $\mathrm{Mn}(0.1 \mathrm{wt} \%)$ content.

Table 1. Chemical composition of the alloys (values in wt.\%). The other elements, e.g. Nb, Cr, Al are in amounts lower than $0.01 \mathrm{wt} . \%$. The balance is iron. Amounts of $\mathrm{MnS}$ and cementite are estimated from Thermo-Calc calculations. ${ }^{45)}$ Pearlite fractions are based on the image analysis of hot-rolled materials.

\begin{tabular}{cccccccccc}
\hline \multicolumn{2}{c}{ Alloy } & $\mathrm{C}$ & $\mathrm{Si}$ & $\mathrm{Mn}$ & $\mathrm{S}$ & $\mathrm{P}$ & $\mathrm{MnS}(\mathrm{vol} \%)$ & Cementite (vol\%) & Pearlite (vol\%) \\
\hline \multirow{5}{*}{ High-Mn } & 0.1Si2Mn & 0.19 & 0.06 & 1.95 & 0.002 & 0.01 & 0.01 & 3 & - \\
& 0.4Si2Mn & 0.20 & 0.39 & 1.96 & 0.002 & 0.01 & 0.01 & 3 & $34 \pm 6$ \\
& 1.0Si2Mn & 0.20 & 0.98 & 2.03 & 0.004 & 0.01 & 0.02 & 3 & $38 \pm 5$ \\
\hline \multirow{3}{*}{ Low-Mn } & 1.5Si2Mn & 0.20 & 1.56 & 2.01 & 0.006 & 0.01 & 0.02 & 3 & 3 \\
& 0.4Si0.1Mn & 0.20 & 0.38 & 0.08 & 0.006 & 0.01 & 0.02 & 3 & $15 \pm 4$ \\
& $1.5 \mathrm{Si} 0.1 \mathrm{Mn}$ & 0.20 & 0.94 & 0.09 & 0.006 & 0.01 & 0.02 & 3 & - \\
\hline
\end{tabular}


our case, we can expect similar microstructure properties after cold rolling reductions.

Annealing experiments were conducted using cold-rolled strip as feedstock. The heating rates used in the present study are $0.1^{\circ} \mathrm{C} / \mathrm{s}, 1^{\circ} \mathrm{C} / \mathrm{s}, 5^{\circ} \mathrm{C} / \mathrm{s}$. The heating rates were chosen in order to ensure that the recrystallization is finished before austenite starts to form. Interrupted heat-treatments were performed in order to generate samples for the ex-situ studies of the evolution of the microstructure. In these cases, the samples are quenched using helium gas with approximately $100^{\circ} \mathrm{C} / \mathrm{s}$ over the range between the temperature at which the quench starts and $200^{\circ} \mathrm{C}$. In the temperature range between $200^{\circ} \mathrm{C}$ and room temperature, the samples are cooled with rate of $\sim 8^{\circ} \mathrm{C} / \mathrm{s}$.

\subsection{Recrystallization}

Investigation of the recrystallization process was conducted using two techniques: 1) in-situ high-temperature X-Ray Diffraction (HT-XRD), which allows us to observe the recrystallization process directly and 2) ex-situ microstructure observation with Scanning Electron Microscope (SEM). For the former, a Bruker D8 diffractometer, equipped with an area (2D) sensitive detector GADDS and an Anton Paar heating stage DHS1100, was used. The heating-stage and detector are stationary during heating experiments and therefore oriented in such a way that parts of three main Debye-Scherrer rings of ferrite can be recorded, i.e. the (110), (200) and (211) rings (see Fig. 2(a)). The recorded diffraction rings are afterwards transformed into diffraction spectra where we can observe the change in intensity for each diffraction peak. The change in the (211) peak intensity is used to identify the start and finish temperatures of the recrystallization process since it has the highest signal to noise ratio as a result of texture effects. As the recrystallization process takes place, the intensity
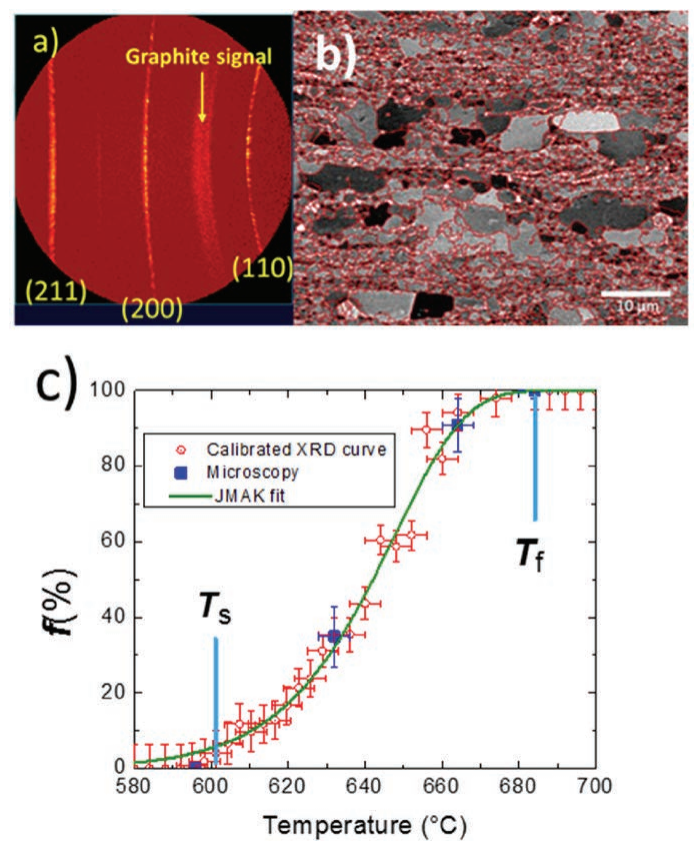

Fig. 2. Methodology for recrystallized volume fraction determination. A) Raw XRD-pattern at $\mathrm{T}=720^{\circ} \mathrm{C}$, B) SEM-BSE image of the partially recrystallized microstructure with grain boundaries highlighted in red, and C) Recrystallized volume fraction as a function of temperature for alloy $0.1 \mathrm{Si} 2 \mathrm{Mn}$ at a heating rate of $1^{\circ} \mathrm{C} / \mathrm{s}$. (Online version in color.) of the (211)-peak decreases. In the case of other peaks, the changes in the intensity are subtler and hence we use (211) peak intensity for calculations. The microstructure observations (via SEM) of the recrystallization process showed no change in ferrite grain size or morphology within pearlite. Therefore, we are unable to conclude whether the ferrite in the pearlitic regions has recovered or recrystallized. But, as there is no change in grain size of ferrite in pearlitic regions during recrystallization process, we can conclude that the changes in ferrite in pearlitic regions happened at early stages and finished very fast. As the ferrite in pearlite did not grow, it does not affect the volume fraction of ferrite grains with (211) orientation. Therefore, we assume that ferrite in pearlitic regions does not affect our recrystallized fraction analysis from XRD, even though there are different pearlite contents in the alloys considered. The fraction recrystallized as a function of temperature is determined from the changes in intensity of the diffraction patterns that are obtained from the radial integration of the patterns. The deformed ferrite structure results in blurred diffraction rings and the recrystallized ferrite grains show as distinct diffraction spots on the 2D-detector. ${ }^{29,30)}$ The fraction recrystallized as a function of temperature as measured by HT-XRD-data is calibrated to the fraction recrystallized as measured from the microstructural analysis by SEM, see Fig. 2(c).

The ex-situ SEM investigations are performed on sets of 3 down-quenched samples from each alloy with varying recrystallized fraction. In order to evaluate the microstructure, we are using the orientation contrast imaging technique. ${ }^{31,32)}$ The small changes in crystal orientation cause differences in the backscattered electron yield, leading to changes in the local grey scale in the image. ${ }^{31)} \mathrm{We}$ are using this effect to identify recrystallized grains, since they should be free from deformation and therefore have a homogeneous grey level. The images are recorded with a JEOL JSM 6500F Scanning Electron Microscope (SEM) equipped with a standard backscattered electron detector (BSE). The photographs are evaluated with the Leica Grain Expert v4.9 software package using grey scale differences as the condition for grain detection (Fig. 2(b)). To obtain statistically relevant numbers of grains we use a threshold of 1000 grains, which results in measuring an area of $\sim 0.06 \mathrm{~mm}^{2}$ for each sample. Another criterion we are using for determining the recrystallized grains is the size. High-resolution images of deformed/recovered areas are taken to determine the deformed cell/sub-grain sizes. This sub-grain size is used afterwards as a minimum above which we can detect recrystallized grains as well as the density of potential nuclei.

\section{Model Description}

\subsection{Solute Drag Effect of Mn \& Si on Early Recrystal- lization Kinetics}

The present section describes the model that we use to interpret the experimental data regarding the solute drag effect of manganese and silicon on the experimentally observed recrystallization start temperatures $T_{s}$. Moreover, an important point to mention is that we have applied our theories and experimental techniques to study the ferrite recrystallization only in the ferritic regions of our steels. Theoretically, the recrystallization start is considered to be 
the moment where grain boundaries start to move. ${ }^{6)}$ Following other researchers, we assume that the potential recrystallization nuclei are recovered dislocation cells/sub-grains. ${ }^{6,33)}$ These dislocation cells/subgrains have low dislocation density within, depending on the recovery stage of course. Here we assume that one of these subgrains would grow favourably to become a nucleus. Based on ideas behind mean field approaches, it is assumed that these potential nuclei/subgrains grow into the surrounding material, which can be represented by the average properties of the material. Some of the nuclei start growing during heating and become recrystallized grains. ${ }^{6,7,34)}$ Differences in the composition of the alloys result in differences in time-temperature combinations at which the recrystallization process starts, since different alloying elements and different concentrations lead to different solute drag pressures. This means that the driving pressures for grain boundary motion are different for different alloys. In alloys with substitutional elements, solute drag can be a major contributor to the reduction or increase of the driving force. ${ }^{21)}$ Therefore, solute drag affects the growth of the nuclei. The general model we are using for the description of the growth of grains during recrystallization is:

$$
d_{j}-d_{i}=\int_{t_{i}}^{t_{j}} V d t=\int_{t_{i}}^{t_{j}} M_{0} F \exp \left(-\frac{E}{R T}\right) d t
$$

where $d_{i}$ and $d_{j}$ represent the diameter of the grains at times $t_{\mathrm{i}}$ and $t_{\mathrm{j}}$, respectively; $V$ is the velocity of the boundary; $M_{o}$ is the pre-exponential factor of the mobility; $F$ is the total driving force for grain boundary motion (which includes solute drag effects that are described later on); $R$ is the universal gas constant; $T$ is the temperature at which the process takes place; $E$ is the activation energy of grain boundary migration; $t_{i}$ and $t_{j}$ are the start and end times of the interval over which recrystallization is considered. Since we are investigating recrystallization during continuous heating, we amend the above equation with the following expression:

$$
T=T_{R T}+\beta t
$$

where $\beta$ is the heating rate and $T_{\mathrm{RT}}$ is room temperature. Modifying the integral with this relationship and using the definition of exponential integrals as described by Farjas, ${ }^{35)}$ we arrive at the following expression:

$$
d_{s}-d_{0}=\frac{M_{0} F R}{\beta E}\left\{\left[T_{s}^{2} \exp \left(-\frac{E}{R T_{s}}\right)\right]-\left[T_{0}^{2} \exp \left(-\frac{E}{R T_{0}}\right)\right]\right\}
$$

The research we are introducing is less focused on the nucleation process and more on the early growth of the nuclei from size $d_{0}$ at temperature $T_{0}$ to a size $d_{\mathrm{s}}$ at temperature $T_{\mathrm{s}}$ at which we can experimentally resolve the start of the recrystallization by means of in-situ XRD during continuous heating. Hence, we are not investigating the change from the deformed state to the beginning of recrystallization. Also due to this constraint we consider $F$ as a constant during the initial stage of recrystallization. However, $\mathrm{F}$ does depend on the composition of the alloy. The sub-grains that we experimentally observe in the SEM-samples shortly after the recrystallization started in other parts of the specimen are considered as potential nuclei with diameter $d_{0}$ (see section 4 and Fig. 8). We define the temperature at which the bound- aries of the nuclei start to migrate as $T_{0}$ (Eq. (3)). We then assume that the $T_{0}$-temperature is, to a first approximation, the same for the seven alloys for a given heating rate and therefore not influenced by the solute drag. We acknowledge that different alloying elements can lead to changes in the microstructure during and after hot rolling - mainly in terms of different pearlite content and grain sizes. Nevertheless, in $\operatorname{Ref}^{28)}$ and Ref, ${ }^{36)}$ Tanaka and Nakashima show that even with different grain sizes and alloying elements, alloys reach a saturation point of dislocation density after higher cold rolling reductions. Moreover, the work of Shintani et $a{ }^{37)}$ also shows that different phases tend to have similar dislocation densities after higher cold rolling reductions. These factors allow us to assume that the stored energy of deformation is in the same range for all the alloys considered in this research. Thus, we assume $T_{o}$ to be the same for all the alloys. However, $T_{\mathrm{o}}$ is assumed to change with heating rate, since the interface cannot instantaneously respond to a change in temperature during continuous heating. Therefore, higher heating rates will shift $T_{0}$ to higher temperatures.

The limitations of the experimental techniques we are using do not allow us to measure accurately the $T_{0}$ temperature directly. Therefore, we use the following procedure to estimate it. Taking into account the instrumental errors and that we only record fragments of the Debye-Scherrer rings, we assume the recrystallized fraction is detectable from approximately $f=0.1$. Therefore, the measured $T_{S}$ temperature is actually temperature at which we have $10 \mathrm{vol} \%$ recrystallized ferrite. Clearly, the experimentally observed recrystallization start temperature $T_{s}$ is dependent on the alloying, so we first estimate $T_{s}$ for a $\mathrm{Fe}-\mathrm{C}$ alloy without $\mathrm{Si}$ and with low Mn content (0Si0.1Mn alloy). We assume the driving force $(F)$ for this alloy will not have any (or negligible) solute drag effects due to $\mathrm{Si}$ and $\mathrm{Mn}$. Hence, we extrapolate $T_{\mathrm{S}}$ for the $0 \mathrm{Si} 0.1 \mathrm{Mn}$ alloy from the series of measurements of the low-Mn alloys with variable Si (presented in section 4 in Fig. 4). The estimation of the average size $d_{s}$ of the grains at a recrystallized fraction $f=0.1$ is done via:

$$
d_{s}=\sqrt[3]{\frac{6 f}{N \pi}}
$$

where $N$ is the number density of active nuclei. In order to

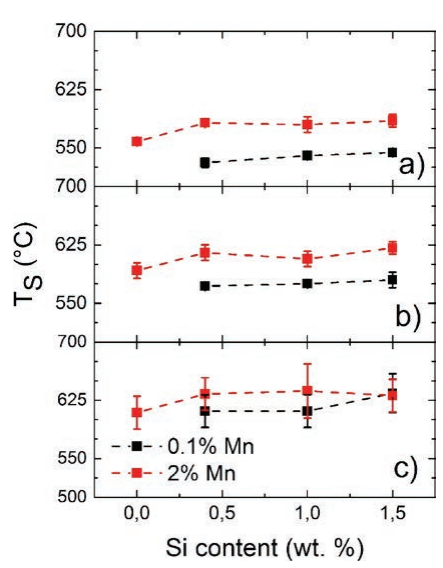

Fig. 3. Recrystallization start temperature (Ts) as function of $\mathrm{Si}$ and $\mathrm{Mn}$ concentrations and heating rates of a) $0.1^{\circ} \mathrm{C} / \mathrm{s}$ b) $1{ }^{\circ} \mathrm{C} / \mathrm{s}$, and c) $5^{\circ} \mathrm{C} / \mathrm{s}$. The silicon content here is the nominal $\mathrm{Si}$ content and not the local Si content in ferrite. (Online version in color.) 
calculate the number density of active nuclei at different heating rates (and consequently temperatures), the following equation is used:

$$
N=N_{0} \exp \left(-\frac{E}{R T_{s}}\right)
$$

The number of recrystallized grains at early stages of recrystallization for $1{ }^{\circ} \mathrm{C} / \mathrm{s}$ (presented in section 4 in Fig. 10) and the extrapolated $T_{s}$ for the $0 \mathrm{Si} 0.1 \mathrm{Mn}$ alloy at different heating rates are used to calculate $N_{o}$. The values and constants used for this calculation are listed in Table 2. With the resulting $d_{s}$ values and the parameters listed in Tables 2 and $\mathbf{3}$, we are able to calculate $T_{0}$ temperature for 0Si0.1Mn alloy (see Table 2). The remaining component to be calculated for Eq. (3) is the driving force for boundary movement. The main components of $F$ in case of unalloyed steel are assumed to be grain boundary curvature and stored energy. The general equation for the driving force for boundary movement for alloyed steel is given by the following equation: ${ }^{38}$

$$
F=G b^{2} \rho+2 \frac{\gamma}{d_{0}}-P_{d}-2 \frac{\gamma_{r e x}}{d_{\text {rex }}}-P_{z}
$$

where $G$ is the shear modulus; $b$ is the Burgers vector; $\rho$ is the dislocation density; $\gamma$ is the surface energy of the grain boundaries of the growing nuclei; $d_{0}$ is the diameter of the potential nuclei; $P_{d}$ is the solute drag force; $\gamma_{r e x}$ is the grain boundary energy of recrystallized grains; $d_{\text {rex }}$ is the diameter of the recrystallized grains; $P_{z}$ is the Zener drag, i.e. the force exerted on the migrating interface by precipitates. Since we are considering the growth at the initial stage, the term $\gamma_{\text {rex }} /$ $d_{\text {rex }}$ can be neglected compared to the $\gamma / d_{0}$ term. At the initial stage, it is assumed that there are potential nuclei which are growing to become recrystallized grains. Therefore, there are no recrystallized grains existing at this stage. As mentioned before, we are studying the recrystallization of ferrite only in the ferritic regions of our materials. Additionally, due to the choice of alloys we have no or very low volume fractions of MnS - see Appendix A and Table 1 - precipitates in our materials. Spherical cementite that formed during the annealing process could have contributed to Zener pinning (accord-

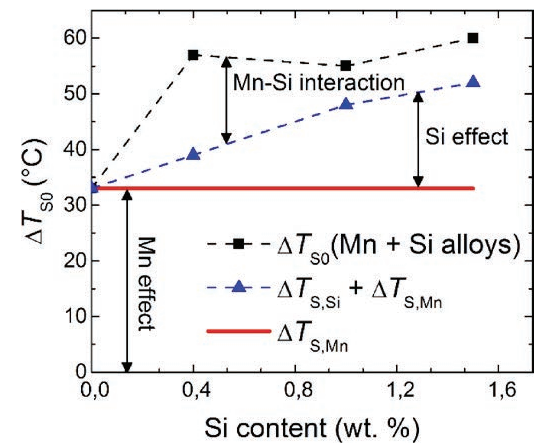

Fig. 4. The increase in the recrystallization start temperature $\Delta \mathrm{T}_{\mathrm{s} 0}$ with respect to the reference alloy $0 \mathrm{Si} 0.1 \mathrm{Mn}$ is decomposed in three underlying effects: the pure effect of the addition of appr. $2 \mathrm{wt} . \% \mathrm{Mn}\left(\Delta \mathrm{T}_{\mathrm{s}, \mathrm{Mn}}\right)$, the pure effect of the silicon concentration $\left(\Delta \mathrm{T}_{\mathrm{s}, \mathrm{Si}}\right)$, and the effect of the $\mathrm{Mn}-\mathrm{Si}$ interaction for the case of a heating rate of $0.1{ }^{\circ} \mathrm{C} / \mathrm{s}$. See text for further definitions. The silicon content here is the nominal Si content and not the local Si content in ferrite. (Online version in color.) ing to calculations in Appendix A). Since we examine only ferritic regions, the cementite in pearlite does not play a huge role here. Therefore, the Zener drag can be assumed to be null. Hence, the last two terms of the equation can be neglected. While the potential subgrain/nucleus grows, we assume that it grows into surroundings, which represent the average properties of the material. Therefore, the driving force in that case can be represented by difference of stored energy across the subgrain boundaries. This is represented by the first term of the Eq. (6). The only unknown parameter remaining in the Eq. $(6)$ is the solute drag $\left(P_{d}\right)$. Among the

Table 2. Model parameters used for calculating the grain growth

\begin{tabular}{|c|c|c|}
\hline \multicolumn{3}{|c|}{ Parameters from literature and experimental } \\
\hline \multicolumn{2}{|c|}{$E$} & $162 \mathrm{~kJ} / \mathrm{mol}$ \\
\hline \multicolumn{2}{|l|}{$M_{o}$} & $1 \times 10^{-4} \mathrm{~m}^{4} /(\mathrm{J} . \mathrm{s})$ \\
\hline \multicolumn{2}{|l|}{$G$} & $79 \mathrm{GPa}$ \\
\hline \multicolumn{2}{|l|}{$b$} & $0.248 \mathrm{~nm}$ \\
\hline \multicolumn{2}{|l|}{$\rho^{28)}$} & $1 \times 10^{15} m^{-2}$ \\
\hline \multicolumn{2}{|l|}{$\gamma$} & $0.5 \mathrm{~J} / \mathrm{m}^{2}$ \\
\hline \multicolumn{2}{|l|}{$N\left(\right.$ for heating rate $\left.1^{\circ} \mathrm{C} / \mathrm{s}\right)$} & $5 \times 10^{15} \mathrm{~m}^{-3}$ \\
\hline \multicolumn{2}{|l|}{$N_{o}\left(\right.$ for heating rate $\left.1^{\circ} \mathrm{C} / \mathrm{s}\right)$} & $6.26 \times 10^{25} \mathrm{~m}^{-3}$ \\
\hline \multirow{2}{*}{$\begin{array}{l}\text { Interaction energy of solute with } \\
\qquad \alpha / \alpha \text { boundary }\end{array}$} & $E_{M n}$ & $\begin{array}{c}-8 \pm 4,^{46)}-2.5^{24)} \\
\text { Assumed }-9 \mathrm{~kJ} / \mathrm{mol}\end{array}$ \\
\hline & $E_{S i}$ & $\begin{array}{c}-15 \pm 2,,^{47)}-4 \text { to }-16,{ }^{48)} \\
-9^{24)} \text { Assumed }-10 \mathrm{~kJ} / \mathrm{mol}\end{array}$ \\
\hline \multirow{2}{*}{ Wagner Interaction Parameters ${ }^{20)}$} & $\varepsilon_{\mathrm{SiC}}$ & 8 \\
\hline & $\varepsilon_{\mathrm{MnC}}$ & -7.5 \\
\hline \multicolumn{2}{|c|}{$\begin{array}{c}D_{0}^{M n} \text { of } \mathrm{Mn}^{49)} \text { in temperature range } \\
800-900^{\circ} \mathrm{C}\end{array}$} & $3.5 \times 10^{-5} \mathrm{~m}^{2} / \mathrm{s}$ \\
\hline \multicolumn{2}{|c|}{$D_{0}^{S i}$ of $\mathrm{Si}^{49)}$ in T range of $900-1434^{\circ} \mathrm{C}$} & $7.35 \times 10^{-5} \mathrm{~m}^{2} / \mathrm{s}$ \\
\hline \multicolumn{2}{|c|}{$\delta$} & $5 \times 10^{-10} \mathrm{~m}$ \\
\hline \multicolumn{3}{|c|}{ Calculated parameters } \\
\hline \multirow{3}{*}{$T_{s, c}$} & $0.1^{\circ} \mathrm{C} / \mathrm{s}$ & $525^{\circ} \mathrm{C}$ \\
\hline & $1^{\circ} \mathrm{C} / \mathrm{s}$ & $565^{\circ} \mathrm{C}$ \\
\hline & $5^{\circ} \mathrm{C} / \mathrm{s}$ & $600^{\circ} \mathrm{C}$ \\
\hline \multirow{2}{*}{$N$} & $0.1^{\circ} \mathrm{C} / \mathrm{s}$ & $1 \times 10^{15} \mathrm{~m}^{-3}$ \\
\hline & $5^{\circ} \mathrm{C} / \mathrm{s}$ & $1 \times 10^{16} \mathrm{~m}^{-3}$ \\
\hline \multirow{3}{*}{$d_{s}$} & $0.1^{\circ} \mathrm{C} / \mathrm{s}$ & $5.75 \mu \mathrm{m}$ \\
\hline & $1^{\circ} \mathrm{C} / \mathrm{s}$ & $3.36 \mu \mathrm{m}$ \\
\hline & $5^{\circ} \mathrm{C} / \mathrm{s}$ & $2.67 \mu \mathrm{m}$ \\
\hline \multirow{3}{*}{$T_{0}$} & $0.1^{\circ} \mathrm{C} / \mathrm{s}$ & $468^{\circ} \mathrm{C}$ \\
\hline & $1{ }^{\circ} \mathrm{C} / \mathrm{s}$ & $500^{\circ} \mathrm{C}$ \\
\hline & $5^{\circ} \mathrm{C} / \mathrm{s}$ & $550^{\circ} \mathrm{C}$ \\
\hline
\end{tabular}
including the solute drag effect (Eqs. (1)-(19)).

Table 3. Activation energy values for self-diffusion of Fe in ferrite (Q) as obtained from DICTRA and the activation energy for grain boundary migration $\left(\mathrm{Q}_{\mathrm{BM}}\right)$, which is considered to be half of the activation energy for self-diffusion.

\begin{tabular}{ccc}
\hline Alloy & Q $(\mathrm{kJ} / \mathrm{mol})$ & $\mathrm{Q}_{\mathrm{BM}}(\mathrm{kJ} / \mathrm{mol})$ \\
\hline 0.1Si2Mn & 332 & 166 \\
0.4Si2Mn & 330 & 165 \\
1.0Si2Mn & 327 & 163 \\
1.5Si2Mn & 325 & 162 \\
0.4Si0.1Mn & 324 & 162 \\
1.0Si0.1Mn & 320 & 160 \\
$1.5 \mathrm{Si} 0.1 \mathrm{Mn}$ & 317 & 159
\end{tabular}


analytical models for calculating the solute drag, Cahn's ${ }^{21)}$ and Hillert's ${ }^{22)}$ models are commonly used. Conceptually, the models are different. The model of Cahn considers the force that solute atoms exert on the migrating interface. The model of Hillert considers the dissipation of Gibbs energy caused by the diffusion of the solute atoms being dragged along with the migrating interface. In the case of grain growth in a single phase material, the model of Cahn, which is mathematically more simple, gives the same results as the model of Hillert. ${ }^{22)}$ Therefore, in present work Cahn's model is used for solute drag calculations. In this model the solute drag pressure/force is given by:

$$
P_{d}=\sum_{i} P_{d, i}=\sum_{i} \frac{\alpha V x_{i}}{1+\beta^{2} V^{2}}
$$

where $P_{d, i}$ is the solute drag force of the $i^{\text {th }}$ alloying element; $V$ is the boundary velocity (calculated from the grain growth data); $x_{i}$ is the concentration of the $i^{\text {th }}$ solute element at the boundary; $\alpha$ and $\beta$ are given by:

$$
\begin{gathered}
\alpha=\frac{N_{v}\left(K_{B} T\right)^{2}}{E_{0 i} D}\left[\sinh \left(\frac{E_{0 i}}{K_{B} T}\right)-\frac{E_{0 i}}{K_{B} T}\right] \ldots \ldots \ldots \ldots . . . \\
\beta^{2}=\frac{\alpha k T \delta}{2 N_{v} E_{0 i}^{2} D} \ldots \ldots \ldots \ldots \ldots \ldots \ldots \ldots \ldots \ldots \ldots \ldots \ldots \ldots \ldots
\end{gathered}
$$

where $N_{v}$ is the number of atoms per unit volume $\left(2 / a^{3}\right.$ for BCC materials); $K_{B}$ is the Boltzmann constant; $E_{0 i}$ is the interaction energy of the solute with the boundary (at the centre of the boundary); $D$ is the diffusion coefficient; $\delta$ is the width of the grain boundary. The total solute drag is calculated by adding the $P_{i}$ from the different alloying elements together, as given by Eq. (7). The concentration of a particular solute at the centre of the boundary is assumed to be a function of $E_{0 i}$, described by Cahn for a stationary boundary. We use this assumption as well for our case of moving boundaries:

$$
x_{i}=x_{0} \exp \left(-\frac{E_{0 i}}{R T}\right)
$$

where, $x_{i}$ is the concentration of the solute at the boundary; $x_{o}$ is the bulk concentration of the solute. The variation of the chemical potential of the solute atoms as a function of distance in the region of the grain boundary is assumed following previous studies - to be a triangular potential. ${ }^{20-22)}$ Assuming a dilute solution, the chemical potential $\mu_{\mathrm{i}}$ of solute $i$ in the centre of the grain boundary region of a single phase material can be written in reference to the chemical potential in ferrite as:

$$
\mu_{i}=R T \ln x_{i}+E_{0 i}
$$

In case the solute atoms are absorbed by the grain boundary, then $E_{0 \mathrm{i}}$ is taken to be negative. However, different solute atoms in the grain boundary interact with each other and thus have an effect on the chemical potential of the solute $i$ in the grain boundary. Therefore, $E_{0 i}$ should also include this interaction effect. Following Guo and Enomoto, ${ }^{20)}$ this interaction can be taken into account as follows:

$$
\mu_{i}=R T\left(\ln x_{i}+\sum_{j=1}^{3} \varepsilon_{i j} x_{j}\right)+E_{i}
$$

where $\varepsilon_{i j}$ is the Wagner interaction parameter of the solutes $i$ and $j$ (where $j=1,2$ and 3 for $\mathrm{Si}, \mathrm{Mn}$ and $\mathrm{C}$ respectively). Note, that, because they studied the solute drag effect during the austenite-to-ferrite phase transformation, Guo and Enomoto $^{20)}$ include an additional term $\Delta E_{\mathrm{i}}$ to indicate the potential step between the ferrite and the austenite. The additional term $\Delta E_{\mathrm{i}}$ is not needed in our case, since we are studying recrystallization (i.e. we have only one phase). By comparing Eqs. (11) and (12), we obtain the following expression for the interaction energy between solute $i$ and the grain boundary:

$$
E_{0 i}=\sum_{j=1}^{3} \varepsilon_{i j} x_{j}+E_{i}
$$

which takes into account the interactions between different solute atoms in the grain boundary. This is in addition to the attractive/repulsive energy $E_{\mathrm{i}}$ experienced by solute atoms with the grain boundary. The parameters $T_{0}, E_{i}$ and $\varepsilon_{i j}$ are the input parameters for our calculations along with the concentration profile at the boundary. The Wagner interaction parameters between the same type of atoms, i.e. $\mathrm{Si}-\mathrm{Si}$, $\mathrm{Mn}-\mathrm{Mn}$ are not included, since the $E_{i}$-parameters contain these interaction coefficients. ${ }^{20)}$ The Wagner parameters used in this study are listed in Table 2. Many publications tend to use $E_{i}$, either as a fitting parameter or by adopting values from the open literature. ${ }^{24)}$ Although there are some experimentally derived values of $E_{i}$, as shown in the Table 2, there are rather large differences. For the current calculations we assume single values of $E_{M n}$ and $E_{S i}$ (see Table 2). By doing so, we arrived at reasonable range of fitted values for $\varepsilon_{M n S i}$. Once the concentration at the boundary is calculated, the solute drag is derived using Cahn's general formula. ${ }^{21)}$

Some authors have also treated the diffusion coefficient as a fitting parameter. ${ }^{24)}$ Here it is assumed that the solute drag depends on the way in which the solute atoms follow the boundary. The solute atoms would attempt to travel across the grain boundary and their diffusion is closely related to bulk diffusion. ${ }^{39)}$ The majority of the diffusion is in the bulk and thus assumed constant. All equations from (7) to (13) are used to calculate the solute drag pressure, which is used as input for Eq. (6). Given the value for the driving force and the grain size as estimated from Eqs. (4) and (5), the Eqs. (1) to (3) result in calculating recrystallization start temperature $T_{\mathrm{s}, \mathrm{c}}$. The Wagner parameter for the $\mathrm{Mn}-\mathrm{Si}$ interaction, $\varepsilon_{M n S i}$ is used as a fitting parameter when comparing calculated $T_{\mathrm{s}, \mathrm{c}}$ and measured $T_{\mathrm{s}}$ recrystallization temperatures.

\subsection{Grain Growth Rate Calculations}

The present section describes the model that we use to estimate the average grain growth rate (grain boundary velocity) from the fraction recrystallized as measured by XRD from the start to the end of the recrystallization process. The recrystallized fraction $f$ is given by the nonisothermal JMAK equation: ${ }^{35)}$

$$
f=1-\exp \left\{-\left[k_{0} \frac{E}{\beta K_{B}} p\left(\frac{E}{K_{B} T}\right)\right]^{m+1}\right\} \ldots \ldots \ldots
$$

where $E$ is the activation energy, which is assumed to be the same for nucleation and growth in this (isokinetic) case; $\beta$ is the heating rate; $K_{B}$ is the Boltzmann constant; $m+1$ 
is the Avrami exponent; $T$ is the temperature. The function $p(x)$ is defined as: ${ }^{34)}$

$$
p(x)=\int_{x}^{\infty} \frac{\exp (-u)}{u^{2}} d u
$$

The rate constant $k_{o}$ is given by: ${ }^{35)}$

$$
k_{0}=\left[\frac{\sigma N_{0}}{m+1}\left(g_{0}\right)^{m}\right]^{\frac{1}{m+1}}
$$

where $\sigma$ is the shape factor ( $\frac{4 \pi}{3}$ for spherical grains); $N_{o}$ is the pre-exponential term in the nucleation rate equation (see Eq. (5)); $g_{o}$ is the pre-exponential factor of the grain growth rate equation. The pre-exponential factors of growth rate can be derived from the equation: ${ }^{35}$

$$
g=g_{0} \exp \left(-\frac{E}{R T}\right)
$$

The grain growth rate $g$ is generally defined as a function of mobility and driving force, ${ }^{40}$

$$
g=M F=M_{0} F \exp \left(-\frac{E}{R T}\right)
$$

By combining Eqs. (17) and (18) we end up with the following expression:

$$
g_{0}=M_{0} F
$$

Therefore, from the rate constant $k_{0}$ of the JMAK-equation, the term $g_{o}$ can be derived. Further multiplication with the exponential term, leads to calculation of the average velocity of the grain boundary from fitting the JMAK equation to the experimentally observed fraction recrystallized as a function of temperature. The average grain boundary velocity obtained from the fit of the JMAK-model to the XRD measurements will be compared to the grain boundary velocities at the intermediate and later stages of recrystallization as determined from the grain growth measurements from the SEM images.

\section{Results and Discussion}

\subsection{Alloying \& Heating Rate Effects on Recrystalliza- tion Start Temperatures}

The experimentally observed recrystallization start temperatures $T_{s}$ are shown in Fig. 3. The $T_{\mathrm{s}}$ temperature depends to a large degree on the Mn concentration and the heating rate. The effect of the Si content is subtler (see following section). The differences in the recrystallization start temperature between the low- (0.1 wt.\%) and high-Mn (2.0 wt.\%) alloys with comparable $\mathrm{Si}$ content varies between 0 and $50^{\circ} \mathrm{C}$. It depends mainly on the heating rate and to some extent on the silicon concentration. Increasing the heating rate from $0.1^{\circ} \mathrm{C} / \mathrm{s}$ to $5^{\circ} \mathrm{C} / \mathrm{s}$ decreases the difference in recrystallization start temperature between the low- and high-Mn alloys from $40-50^{\circ} \mathrm{C}$ to $0-20^{\circ} \mathrm{C}$, depending on the silicon concentration.

For the alloys with approximately $0.1 \mathrm{wt} . \% \mathrm{Mn}$, the effect of the $\mathrm{Si}$ concentration on the $T_{\mathrm{s}}$ temperature is relatively small (see Fig. 3). The $T_{\mathrm{s}}$ rises by about $10^{\circ} \mathrm{C}$ when the $\mathrm{Si}$ concentration is increased from $0.4 \mathrm{wt} . \%$ to $1.5 \mathrm{wt} . \%$. The heating rate does not have big effect as well in this case. For the high-Mn alloys the effect of the silicon concentra- tion on the $T_{\mathrm{s}}$ temperature is different. The addition of 0.4 wt.\% Si leads to an increase of the recrystallization start temperature of about $20-25^{\circ} \mathrm{C}$ when heating rate is 0.1 and $1{ }^{\circ} \mathrm{C} / \mathrm{s}$. The higher addition of silicon (up to $1.5 \mathrm{wt} . \%$ ) does not significantly change the recrystallization start temperature in those alloys.

We would like to quantify the effects of the Si and Mn concentrations and the interaction between the $\mathrm{Si}$ and $\mathrm{Mn}$ atoms on the recrystallization start temperature. As a reference point, we use recrystallization start temperature of a theoretical alloy 0 wt.\% Si and 0.1 wt.\% Mn. Since we did not have such material, we estimated the $T_{s}$ by extrapolating the measured $T_{s}$ values of low-Mn alloys to a point with 0 wt.\% Si (see Fig. 3). The process is done for all three heating rates. We refer to this imaginary alloy as $0 \mathrm{Si} 0.1 \mathrm{Mn}$. The estimated values for $T_{\mathrm{s}}$ for this alloy are given in Fig. 5 . The increase in the recrystallization start temperature $\Delta T_{s 0}$ of the alloys with $2.0 \mathrm{wt} . \% \mathrm{Mn}$ and different Si concentrations with respect to the alloy without silicon and with little manganese is defined as:

$$
\Delta T_{s 0}=T_{s, x S i 2 M n}-T_{s, 0 S i 0.1 M n}
$$

where $x$ stands for the Si concentration in the alloy. The effects of the overall $\mathrm{Si}$ and $\mathrm{Mn}$ concentrations as well as the effect of the Si-Mn interaction on $\Delta T_{s 0}$ are shown in Fig. 4 for the case of a heating rate of $0.1{ }^{\circ} \mathrm{C} / \mathrm{s}$. The total $\Delta T_{s 0}$ can be decomposed into the following components:

$$
\Delta T_{s 0}=\Delta T_{s, M n}+\Delta T_{s, S i}+\Delta T_{s, M n-S i}
$$

where $\Delta T_{s, M n-S i}$ is the contribution from the interaction between $\mathrm{Mn}$ and Si atoms; $\Delta T_{s, M n}$ is the contribution of only $\mathrm{Mn}$ and $\Delta T_{s, S i}$ is the contribution of only the Si to the $\Delta T_{s 0}$. The effect of only the Mn concentration on the change in $T_{\mathrm{s}}$ can be calculated as follows:

$$
\Delta T_{s, M n}=T_{s, 0.1 S i 2 M n}-T_{s, 0 S i 0.1 M n} \approx 33^{\circ} \mathrm{C}
$$

where we consider the $T_{\mathrm{s}}$ of the $0.1 \mathrm{Si} 2 \mathrm{Mn}$ alloy and the estimated $T_{\mathrm{s}}$ of the $0 \mathrm{Si} 0.1 \mathrm{Mn}$ alloy, respectively. Similarly, $\Delta T_{s, S i}$ can be calculated as:

$$
\Delta T_{s, S i}=T_{s, x S i 0.1 M n}-T_{s, 0 S i 0.1 M n} \approx 19^{\circ} \mathrm{C}(\text { for } x=1.5 w t . \% S i)
$$

In this case we use the alloys with $0.1 \mathrm{wt} . \% \mathrm{Mn}$, since we assume that the effect of the $\mathrm{Mn}-\mathrm{Si}$ interaction is negligibly small in these alloys.

The effect of the Mn-Si interaction on the $T_{\mathrm{s}}$ temperature

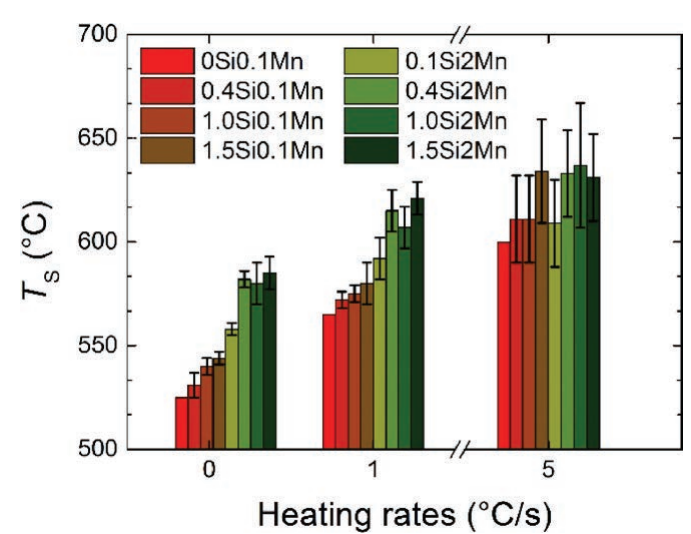

Fig. 5. Effect of heating rate and alloying on the recrystallization start temperature $\left(\mathrm{T}_{\mathrm{s}}\right)$. (Online version in color.) 
can then be derived from the difference between the measured $\Delta T_{s 0}$ and $\left(\Delta T_{s, M n}+\Delta T_{s, S i}\right)$ (see Fig. 4). The effectiveness of the $\mathrm{Mn}-\mathrm{Si}$ interaction on the $T_{\mathrm{s}}$ temperature reaches its maximum with $\mathrm{Si}$ addition of 0.4 wt. $\%$ and decreases with further increase of the silicon content. The collective contribution of the $\mathrm{Si}$ and $\mathrm{Mn}$ atoms to the initial increase in $T_{s}$ is higher than what would be expected from a simple sum of their individual contributions. It shows that the interaction between $\mathrm{Si}$ and $\mathrm{Mn}$ atoms leads to an additional increase in the recrystallization start temperature.

The heating rate also affects the $T_{s}$ temperature, which can be seen in Fig. 5. Overall, the $T_{s}$ increases linearly with increasing heating rate. The effect seems to be stronger for the alloys with $0.1 \mathrm{wt} . \% \mathrm{Mn}$ than for the alloys with 2.0 wt. $\% \mathrm{Mn}$. As an example, the $T_{s}$ of $0.4 \mathrm{Si} 0.1 \mathrm{Mn}$ alloy rises by $\sim 40^{\circ} \mathrm{C}$ when the heating rate is increased first from $0.1^{\circ} \mathrm{C} / \mathrm{s}$ to $1^{\circ} \mathrm{C} / \mathrm{s}$ and then by another $\sim 40^{\circ} \mathrm{C}$ when the heating rate is increased from $1^{\circ} \mathrm{C} / \mathrm{s}$ to $5^{\circ} \mathrm{C} / \mathrm{s}$. In comparison, the $0.4 \mathrm{Si} 2 \mathrm{Mn}$ alloy shows an increase in the recrystallization start temperature by $30^{\circ} \mathrm{C}$ and $20^{\circ} \mathrm{C}$ when increasing the heating rate from $0.1^{\circ} \mathrm{C} / \mathrm{s}$ to $1^{\circ} \mathrm{C} / \mathrm{s}$ and then from $1^{\circ} \mathrm{C} / \mathrm{s}$ to $5^{\circ} \mathrm{C} / \mathrm{s}$, respectively. As a result, the difference in recrystallization start temperature $\left(\Delta T_{s}\right)$ between the alloys with 2 wt. $\%$ and $0.1 \mathrm{wt} . \% \mathrm{Mn}$ with corresponding Si contents, becomes smaller with increasing heating rate (Fig. 3). For example, a change in heating rate from $0.1^{\circ} \mathrm{C} / \mathrm{s}$ to $5^{\circ} \mathrm{C} / \mathrm{s}$, leads to a reduction in $\Delta T_{\mathrm{s}}$ from $50^{\circ} \mathrm{C}$ to $20^{\circ} \mathrm{C}$ for the alloys with 0.4 wt. $\% \mathrm{Si}$.

\subsection{Mn \& Si Effects on Solute Drag and Wagner-inter- action Parameter}

The model described in Section 3.1. allows us to estimate the solute drag pressure by fitting the model to the measured recrystallization start temperatures using $\varepsilon_{M n S i}$. We assume in the calculations that the concentrations of silicon and manganese in the ferrite regions correspond to the overall/ nominal composition of the alloy (although segregation of alloying elements could lead to locally different concentrations). The results are shown in Fig. 6. Following the work in $\mathrm{Ref}^{18)}$ the $\mathrm{Mn}$ and $\mathrm{Si}$ composition of ferrite is a little bit lower than the nominal composition. If the solute drag calculations are done by using the actual ferrite composition, the values would be a little bit different, but the general trend and the theoretical treatment would remain

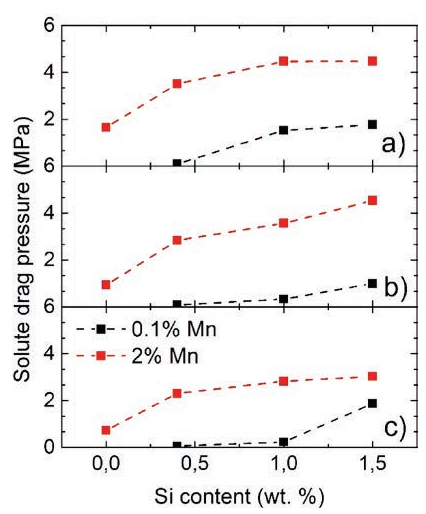

Fig. 6. Solute drag pressure depending on the silicon and manganese concentrations and the 3 heating rates: a) 0.1 , b) 1 , and c) $5^{\circ} \mathrm{C} / \mathrm{s}$. The silicon and $\mathrm{Mn}$ content here are the nominal $\mathrm{Si}$ and $\mathrm{Mn}$ contents and not the local $\mathrm{Si}, \mathrm{Mn}$ content in ferrite. (Online version in color.) the same. The recrystallization start temperature $T_{\mathrm{s}}$ depends on the grain boundary mobility, which in turn depends on the solute drag effect as mentioned before. Therefore, the variations in $T_{\mathrm{s}}$ as shown in Fig. 3 can be explained through variations in the solute drag effect and the activation energy for grain boundary migration. The addition of Si to alloys with 2.0 wt.\% Mn causes significant increase in the solute drag pressure (see Fig. 6). This explains the higher $T_{\mathrm{s}}$ in steels with higher amounts of Si and Mn (see Fig. 3). The solute drag calculations also show that increasing the Si content in alloys with $0.1 \mathrm{wt} . \% \mathrm{Mn}$ increases the solute drag as well, although it is lower than in the alloys containing both $\mathrm{Si}$ and $\mathrm{Mn}$ in higher amounts. Even though the solute drag is increasing with $\mathrm{Si}$ addition in the alloys with $0.1 \mathrm{wt} . \%$ $\mathrm{Mn}$, the activation energy for grain boundary migration is decreasing at the same time according to the literature (see Table 3). This compensates the solute drag effect of $\mathrm{Si}$ and leads to a slow rise in $T_{\mathrm{s}}$ for alloys with $0.1 \mathrm{wt} . \% \mathrm{Mn}$.

If we would assume simple additive effect of $\mathrm{Si}$ and $\mathrm{Mn}$ on solute drag then the sum of the solute drag pressures of alloys $0.1 \mathrm{Si} 2 \mathrm{Mn}$ and $0.4 \mathrm{Si} 0.1 \mathrm{Mn}$ should equate to result of the alloy $0.4 \mathrm{Si} 2 \mathrm{Mn}$. Table 1 shows that when the chemical compositions of the $0.1 \mathrm{Si} 2 \mathrm{Mn}$ and $0.4 \mathrm{Si} 0.1 \mathrm{Mn}$ alloys are added, the result is close to the composition of the $0.4 \mathrm{Si} 2 \mathrm{Mn}$ alloy. However, it can be seen from Fig. 6 that the sum of the solute drag pressures of the two alloys $(0.1 \mathrm{Si} 2 \mathrm{Mn}$ and $0.4 \mathrm{Si} 0.1 \mathrm{Mn}$ ) is lower than that of $0.4 \mathrm{Si} 2 \mathrm{Mn}$ alloy. In other words, a simple addition of the individual contributions of $\mathrm{Si}$ and $\mathrm{Mn}$ to the solute drag pressure doesn't explain the higher collective contribution of the $\mathrm{Si}$ and $\mathrm{Mn}$ concentrations to the solute drag pressures in $\mathrm{Fe}-\mathrm{C}-\mathrm{Mn}-\mathrm{Si}$ alloys. This points to an interaction between $\mathrm{Si}$ and $\mathrm{Mn}$ atoms leading to an additional solute drag pressure, i.e. a coupled solute drag effect.

The calculated solute drag values are very similar (1.7 $\mathrm{MPa}$ ) for the alloys $0.1 \mathrm{Si} 2 \mathrm{Mn}$ and $1.5 \mathrm{Si} 0.1 \mathrm{Mn}$ (see Fig. 6). However, the $T_{\mathrm{s}}$ is quite different for those two alloys. This is due to the higher activation energy for grain boundary migration for the $2.0 \mathrm{wt} . \% \mathrm{Mn}$ alloy (Table 3). When 0.4 $\mathrm{wt} \% \mathrm{Si}$ is added to the alloy with $2.0 \mathrm{wt} . \% \mathrm{Mn}$, the solute drag pressure increases significantly, leading to higher $T_{\mathrm{s}}$. Further additions of Si do not affect the solute drag pressure as much, whereas the activation energy for grain boundary motion decreases with increasing $\mathrm{Si}$ concentration. The combination of these two effects leads to a nearly constant recrystallization start $T_{\mathrm{s}}$ with further additions of $\mathrm{Si}$ to the alloy with $2.0 \mathrm{wt} . \% \mathrm{Mn}$. It should be noted here though, that the exact values for the activation energy for grain boundary motion as a function of composition are also difficult to obtain experimentally.

Higher heating rates delay recrystallization to higher temperatures, as was also observed by Li et al. ${ }^{2)}$ Consequently, the grain growth will take place at higher temperatures, because it is an atomistic process. This also means that the sub-grain growth start temperature $\left(T_{o}\right)$ increases, which has been discussed in section 3.1. At higher temperatures, literature states that the solute drag effect should become smaller. ${ }^{21,22)}$ Our results confirm this hypothesis (see Fig. 6). Hence, the combined solute drag effect of Si and Mn is reduced at higher heating rates. This results in smaller differences in solute drag pressures for the different alloys at higher heating rates, which in turn results in decreasing 
$\Delta T_{s}=T_{S, M n+S i}-T_{s, S i}$ with increasing heating rate. Moreover, the solute drag values of alloys with 2.0 wt. $\%$ Mn reduces more significantly than the alloys with $0.1 \mathrm{wt} . \% \mathrm{Mn}$ with the increase in heating rates. Therefore, the increase in $T_{s}$ due to the increase in heating rate is less pronounced for alloys with $2.0 \mathrm{wt} . \% \mathrm{Mn}$ (due to higher available driving force) than for the alloys with 0.1 wt.\% Mn.

The Wagner interaction parameter is important for determining the solute drag in multi-component systems. As mentioned by Guo et al., ${ }^{20)} \varepsilon_{M n S i}$ needs to be adjusted for different alloys and temperatures. This is because Wagner parameters are quite difficult to obtain experimentally. What's more, they have been mostly determined for binary alloys. Higher order parameters for multi-component alloys are not determined and largely neglected in solute drag calculations since they are quite complicated to obtain. ${ }^{41,42)}$ For the sake of simplicity and following the example of other researchers we use the $\varepsilon_{M n S i}$ as a fitting parameter with the understanding that it is an effective parameter which encompasses higher order Wagner parameters as well. ${ }^{20,24)}$ As expected, $\varepsilon_{M n S i}$ is certainly dependent on temperature and concentration of the solutes, as can be seen in Fig. 7. Moreover, there seems to be a trend in which $\varepsilon_{M n S i}$ increases with increasing Si concentration for the alloys with $2.0 \mathrm{wt} . \% \mathrm{Mn}$. With increasing $\mathrm{Si}$ concentration, there is higher probability of Si interacting with other $\mathrm{Si}$ or $\mathrm{C}$ atoms in the boundary. It is known that $\mathrm{Si}-\mathrm{Si}$ and $\mathrm{Si}-\mathrm{C}$ interactions are both repulsive. ${ }^{19,20)}$ This results in a higher value of the effective $\varepsilon_{M n S i}$. Subsequently, the interaction energy, $E_{0 i}$, between the solutes and the grain boundary increases, consequently reducing the concentration of elements at the grain boundary more than expected. This should result in a reduced contribution of $\mathrm{Si}-\mathrm{Mn}$ interactions to solute drag. As we mentioned before though, these interactions are considered only with respect to the first order terms (Eq. (12)). The higher order terms, which we neglect due to the lack of experimental data ${ }^{20,42)}$ might influence the interaction parameter. It might seem that this idea of interaction between $\mathrm{Si}-\mathrm{Mn}$ leading to an increased solute drag pressure,

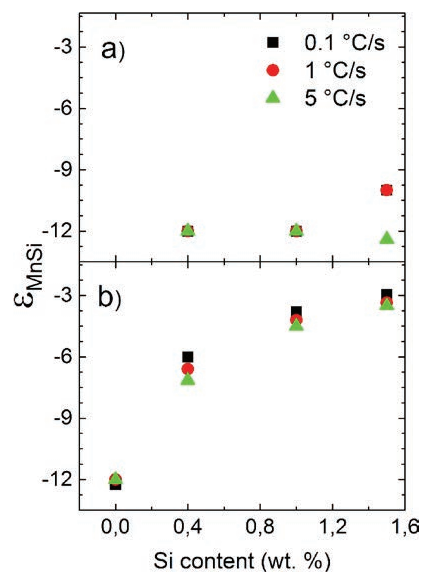

Fig. 7. The Wagner parameter $\varepsilon_{\mathrm{MnSi}}$ for the interaction between $\mathrm{Si}$ and $\mathrm{Mn}$ atoms depending on the silicon and manganese concentrations and the heating rate as determined for two different Mn concentrations: a) 0.1 and b) $2.0 \mathrm{wt} . \% \mathrm{Mn}$. The Wagner parameter $\varepsilon_{\mathrm{MnSi}}$ is obtained from the fit of the model for early grain growth (see text) to the measured recrystallization start temperatures. The silicon and $\mathrm{Mn}$ content here are the nominal $\mathrm{Si}$ and $\mathrm{Mn}$ contents and not the local Si, Mn content in ferrite. (Online version in color.) i.e. a coupled solute drag effect, might be in conflict with results of Qiu et al., ${ }^{24)}$ who observed a decoupled solute drag effect for $\mathrm{Mn}$ and $\mathrm{Si}$ for austenite-ferrite transformations. One of the reasons for these differences could be due to higher carbon content in their alloys, which might be resulting in a much higher $\mathrm{C}$ concentration at the interfaces. As mentioned earlier, the $\mathrm{Si}-\mathrm{C}$ interactions are repulsive and $\mathrm{Mn}-\mathrm{C}$ interactions are attractive. Therefore, this may lead to a possible situation where the Si atoms feel repulsive forces and do not segregate at the interfaces. This point has been mentioned by Qiu et $a l .{ }^{24)}$ The other fact is that Qiu et $a l .{ }^{24)}$ have studied the migration of austenite-ferrite interfaces, whereas we are discussing the migration of ferrite-ferrite interfaces. Different interfaces may lead to different segregation behaviours.

The quantities of the Wagner parameters derived from the experimental results need to be viewed as indicative and not definitive values. The values are affected by the assumptions in the model, neglect of higher order terms and the uncertainty in the values of input parameters. For example, the values of the parameters $E_{M n}$ and $E_{S i}$ (Table 2) have a rather high uncertainty. They have, in turn, strong effect on the final Wagner parameter value. Nevertheless, the general trend, for the change of Wagner parameter with concentrations and temperatures, as explained above, should still hold. Even with the changes in the description of Wagner parameter or the input parameters, the basic physics assumed in the model would not change. Only when the higher order terms are taken into account and the input parameters are accurate themselves, the Wagner parameters values derived from the presented model could be termed accurate.

The solute drag theory can possibly be also used to explain the presence of small sized recrystallized/recovered grains seen in pearlitic regions (Fig. 8). The ferrite grains in these areas are much smaller than the recrystallized grains in the pro-eutectoid ferrite regions. The strip steel production process leads to formation of micro-segregation bands. Usually, pearlite forms in the bands with higher Mn concentration and therefore in those areas due to higher concentration of solute elements, there could be a higher solute drag pressure. ${ }^{18)}$ Competing mechanism for small ferrite grains formation can be growth impedance by the spheroidized cementite, which acts as a barrier for ferrite grain growth ${ }^{43}$ ) in the pearlitic regions observed in this study. Due to restrictions of present studies we did not investigate further which of the mechanisms is prominent in this process.

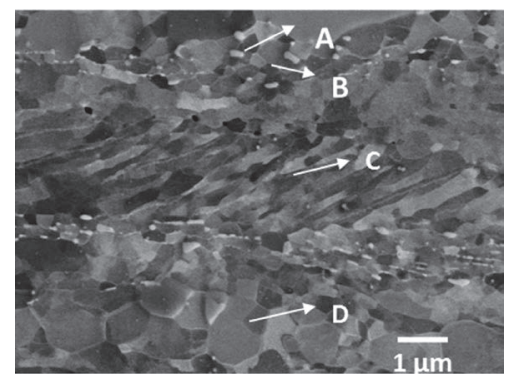

Fig. 8. SEM-BSE image of the microstructures of the $10 \%$ recrystallized 1.5Si2Mn alloy showing A) spheroidized cementite, B) recovered/recrystallized pearlitic ferrite, C) Deformed pro-eutectoid ferrite, and D) Recovered/recrystallized pro-eutectoid ferrite. 


\subsection{Evolution of the Microstructure during Recrystal- lization}

Figure 8 shows an example of the SEM-BSE image of the microstructure at the early stage $(f \approx 0.1)$ of recrystallization. From images like these, we ascertain that the average diameter of the sub-grains is $d_{0}=2 \pm 1 \mu \mathrm{m}$, which we use as an input to our model described in section 3. As mentioned earlier, recovered sub-grains/deformed cells are considered in our model as the potential nuclei for recrystallization. Figure 9 shows SEM images at later stages of recrystallization $(f \approx 0.3$ and $f \approx 0.5)$ in which clusters of recrystallized grains can be observed in a deformed matrix. Figure 10 shows the measured number density of recrystallized grains plotted against the fraction recrystallized. The microstructural observations show that the density of recrystallized grains decreases as the recrystallization process progresses, see Fig. 10. This indicates that some grains are consumed by other growing grains during recrystallization. The reason for the consumption of smaller grains at the start of recrystallization could be due to early impingement (or clustered nucleation) as seen in Fig. 9. Such clustered nucleation or impingement at the start would lead to a dominant recrystallizing grain consuming other slower
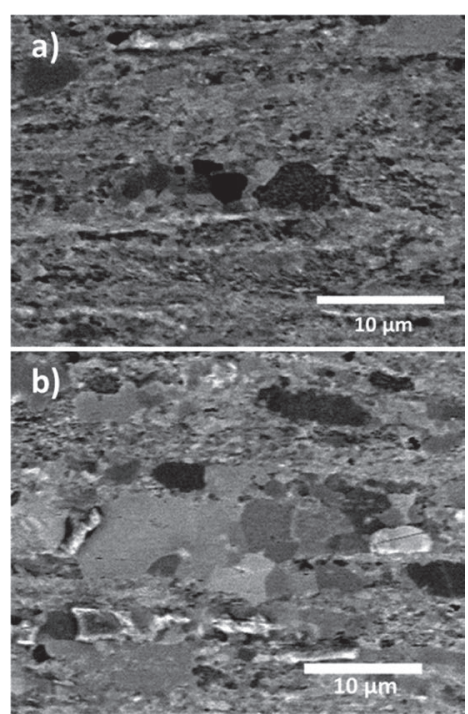

Fig. 9. SEM images showing clustered nucleation of recrystallized ferrite grains in a) $27 \%$ recrystallized sample of alloy $0.4 \mathrm{Si} 2 \mathrm{Mn}$ and b) $50 \%$ recrystallized sample of alloy $0.4 \mathrm{Si} 2 \mathrm{Mn}$.

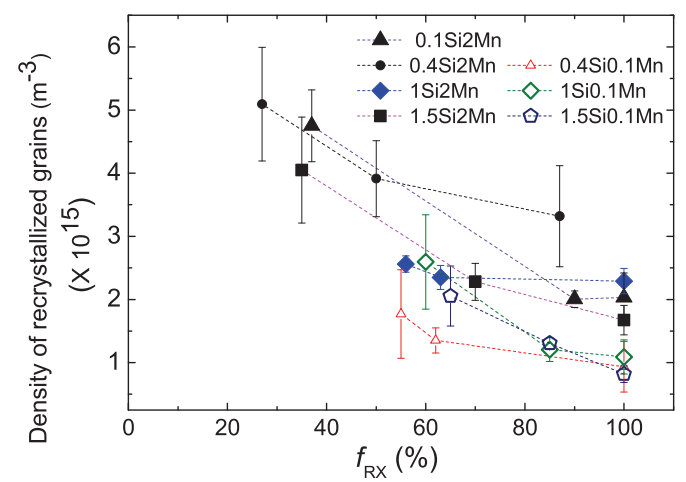

Fig. 10. Number density of recrystallized grains as a function of volume fraction recrystallized for all the studied alloys. (Online version in color.) growing grains. Clustered nucleation takes place due to heterogeneous distribution of stored energy. This has also been observed in the work of Lü et al. ${ }^{33)}$ Figure 11 shows the evolution of the grain size distribution during recrystallization and supports the observation that the smaller grains are consumed in the initial stages of recrystallization.

Figure 10 shows that at the moment that the recrystallized volume fraction reaches approximately $\sim 60 \%$, the number of recrystallized grains no longer changes significantly. This could be due to two possible reasons: a lower driving force for grain growth and the impingement of growing grains. At the later stages of recrystallization, the amount of dislocations is lower and therefore, the overall driving force decreases. Figure 10 shows that impingement of grains is present from the relatively early stages of recrystallization $(f \approx 0.3)$ and impingement takes place more often as the recrystallization progresses $(e . g$. at $f \approx 0.5)$. This effectively reduces the growth of the grains significantly.

Figure 11 shows that the difference between the grain size distribution of a $50 \%$ recrystallized sample and $100 \%$ recrystallized sample is not high. This shows that the major changes in the number of recrystallized grains takes place in the initial stages of recrystallization (up to a recrystallized volume fraction of $50 \%$ ), which is also seen in Fig. 10. The reduction in the number of small grains in the initial phase of recrystallization also suggests that the major growth phase of the recrystallizing grains occurs over the interval up to around $50-60 \%$ recrystallised. The measured grain sizes (from the SEM images) as a function of progress of recrystallization also point to this effect (see Fig. 12). The experimental observation that no significant change in the grain size takes place after 50\% recrystallization, could represent a stage at which most of the recrystallized grains are impinged by other neighbouring recrystallized grains in many directions. ${ }^{7)}$

Figure 12 shows that the growth of the grains in the rolling (RD) and transverse (TD) directions is similar to each other but much higher than the growth in the normal (ND) direction. The grain size in the ND is restricted to the range of $10-15 \mu \mathrm{m}$. This size range is approximately equivalent

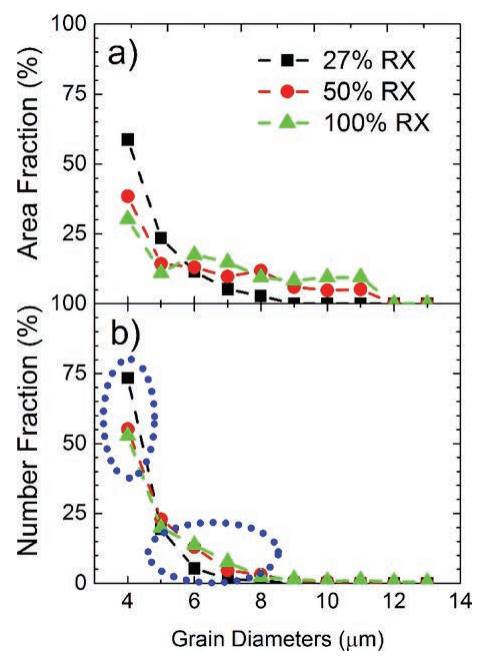

Fig. 11. Grain size distributions for the alloy $0.4 \mathrm{Si} 2 \mathrm{Mn}$ at three different stages of recrystallization (RX) of 27, 50 and $100 \%$ expressed as: a) area and b) number fractions. (Online version in color.) 


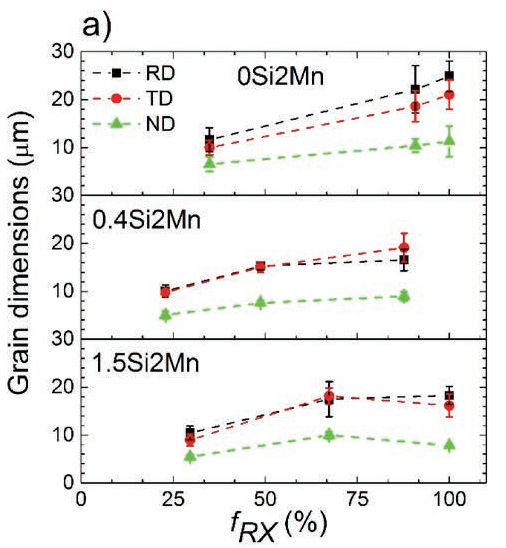

b)

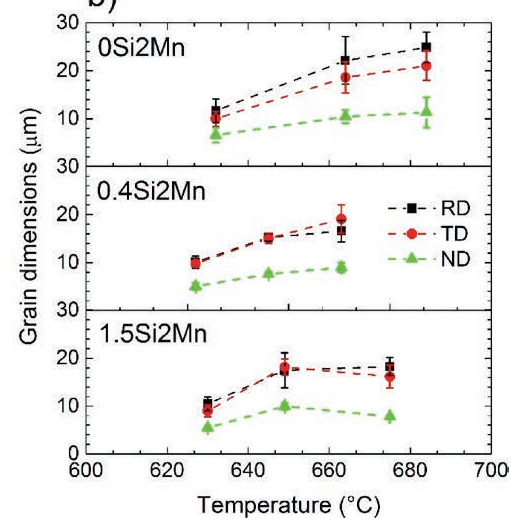

Fig. 12. Recrystallized grain sizes as a function of a) recrystallized volume fraction $f$ and $\mathrm{b}$ ) temperature for the heating rate of $1^{\circ} \mathrm{C} / \mathrm{s}$ for the following alloys: $0 \mathrm{Si} 2 \mathrm{Mn}, 0.4 \mathrm{Si} 2 \mathrm{Mn}$, 1.5Si2Mn. (Online version in color.)

Table 4. Description for the various stages of recrystallization at which the grain growth rate was measured by SEM in the alloys with $2 \mathrm{wt} . \% \mathrm{Mn}$ and three different concentrations of silicon.

\begin{tabular}{ccc}
\hline Alloy & $\begin{array}{c}\text { Stage recrystallization } \\
\text { (qualitatively) }\end{array}$ & $\begin{array}{c}\text { Recrystallized } \\
\text { Volume Fraction (\%) }\end{array}$ \\
\hline $0.1 \mathrm{Si} 2 \mathrm{Mn}$ & Intermediate & $34-90$ \\
& Late & $90-100$ \\
$0.4 \mathrm{Si} 2 \mathrm{Mn}$ & Intermediate & $22-48$ \\
& Late & $48-87$ \\
$1.5 \mathrm{Si} 2 \mathrm{Mn}$ & Intermediate & $29-67$ \\
& Late & $67-100$ \\
\hline
\end{tabular}

to the pearlite band spacing of the alloys, which is measured and published in Ref. ${ }^{18,44)}$

Because the ferrite growth rates in RD and TD directions are comparable and much higher than the growth rate observed for ND direction, only the former was considered in the subsequent analysis of the recrystallization process. It was then compared with the growth rates obtained from the fitting of non-isothermal JMAK model to the volume fraction recrystallized measured by XRD (method described in Section 3.2.). Since the choice of the time-temperature combination for the metallographic samples did not always yield the same amounts of recrystallized ferrite in all alloys we qualitatively refer to two different growth stages during the recrystallization, i.e. 'intermediate' and 'late'. The exact definition of those stages is presented in Table 4. Figure $\mathbf{1 3}$ shows the comparison between the grain growth rates

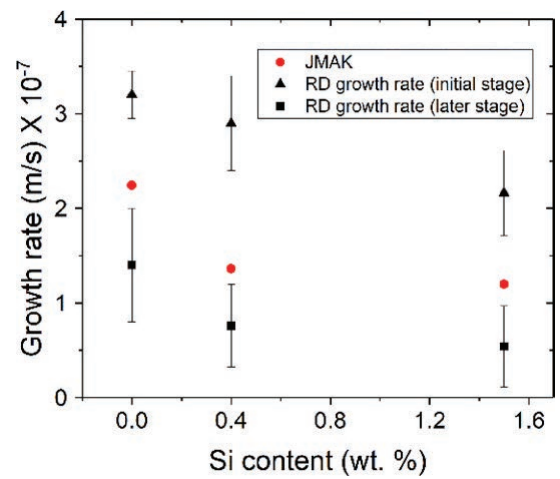

Fig. 13. Grain growth rates depending of the silicon concentration as determined from the SEM-images (solid squares and triangles) for grain growth in the rolling direction (RD) and as determined from the fit of the non-isothermal JMAK model to the measured fraction recrystallized $\mathrm{f}$ as a function of temperature (see Fig. 1(c)) for alloys with 2 wt. $\% \mathrm{Mn}$ at heating rate of $1^{\circ} \mathrm{C} / \mathrm{s}$. (Online version in color.)

derived from both methods. The RD growth rates in intermediate and late stages are different from the growth rates derived from non-isothermal JMAK equation. The latter are in between the intermediate and late stages. This could be because the JMAK accounts for the whole of the recrystallization curve, which includes all the recrystallization stages. The microstructure analysis shows us the intermediate stage is much faster and then as the recrystallization progresses the growth rates reduce significantly (Fig. 13).

\section{Conclusions}

(1) The experimentally observed recrystallization start temperature $T_{\mathrm{s}}$ depends to a large degree on the manganese concentration and the heating rate. The effect of the silicon concentration on the recrystallization start temperature is subtler (see next conclusion). The difference in the recrystallization start temperature between the alloys with $0.1 \mathrm{wt} . \%$ and $2 \mathrm{wt} . \% \mathrm{Mn}$ varies between 0 and $50^{\circ} \mathrm{C}$, which mainly depends on the heating rate and to some extent on the silicon concentration. Increasing the heating rate decreases the difference in recrystallization start temperature between the alloys with 0.1 wt. $\%$ and $2 \mathrm{wt} . \% \mathrm{Mn}$. Increasing the heating rate increases the recrystallization start temperature of each investigated alloy linearly, but with seemingly different slopes for the alloys with $0.1 \mathrm{wt} . \%$ and $2 \mathrm{wt} . \% \mathrm{Mn}$.

(2) The silicon concentration has a significant influence on the recrystallization start temperature only in case of higher Mn concentrations (2 wt.\%) present in the alloy. The addition of $0.4 \mathrm{wt} . \% \mathrm{Si}$ to the alloy with $2 \mathrm{wt} . \% \mathrm{Mn}$ leads to an increase in the recrystallization start temperature of about $20-25^{\circ} \mathrm{C}$ in case the heating rate is 0.1 and $1{ }^{\circ} \mathrm{C} / \mathrm{s}$. The addition of higher concentrations of silicon (up to $1.5 \mathrm{wt} . \%$ ) and/or higher heating rates (up to $5^{\circ} \mathrm{C} / \mathrm{s}$ ) do not significantly change the recrystallization start temperature of the alloy with $2 \mathrm{wt} \% \mathrm{Mn}$. The addition of silicon in concentrations up to $1.5 \mathrm{wt} . \%$ to the alloy with a low $(0.1 \mathrm{wt} . \%)$ Mn concentration does not lead to significant changes in the recrystallization start temperature either. The collective contribution of the $\mathrm{Si}$ and $\mathrm{Mn}$ atoms to the increase in the recrystallization start temperature with respect to the reference alloy (without $\mathrm{Si}$ and with very little $\mathrm{Mn}$ ) is higher than what would be 
expected from the simple addition of the effects of the Si and Mn concentrations. This means that the interaction between $\mathrm{Si}$ and $\mathrm{Mn}$ atoms leads to an additional increase in the recrystallization start temperature, i.e. a coupled solute drag effect.

(3) The experimentally observed differences in recrystallization start temperature, which depend on the manganese and silicon concentrations and on the heating rate, can be reproduced by combining the non-isothermal JMAK grain growth model as described by Farjas and the model of Cahn for the description of the solute drag effect, in case the following modification/extension is made to the model of Cahn: the interaction energy of the solute atoms with the moving boundary is made dependent on the manganese and silicon concentrations and on the Wagner interaction parameters. The effective Wagner-parameter $\varepsilon_{M n S i}$ for the $\mathrm{Mn}-\mathrm{Si}$ interaction, which depends on the silicon concentration and temperature, is used as a fitting parameter in this study.

(4) Clustered (non-random) nucleation is observed. Moreover, there is a large difference in the average growth rates of the grains in the intermediate and later stages of recrystallization as observed by SEM-analysis. The growth rates in the RD- \& TD-directions are similar, whereas growth of recrystallizing grains in the ND-direction is interrupted due to early impingement with pearlite bands. The non-random nucleation, early impingement of the grains in the ND-direction and non-constant growth rates of recrystallizing grains observed in this work are against the basic assumptions of the non-isothermal JMAK model, which implies the need of a more comprehensive model to describe the evolution of the microstructure during the intermediate and later stages of recrystallization.

\section{REFERENCES}

1) N. Fonstein: Advanced High Strength Sheet Steels, Springer International Publishing, Cham, (2015), 1.

2) P. Li, J. Li, Q. Meng, W. Hu and D. Xu: J. Alloy. Compd., 578 (2013), 320

3) A. Chbihi, D. Barbier, L. Germain, A. Hazotte and M. Gouné: J. Mater. Sci., 49 (2014), 3608.

4) J. Huang, W. J. Poole and M. Militzer: Metall. Mater. Trans. A, 35 (2004), 3363.

5) R. R. Mohanty, O. A. Girina and N. M. Fonstein: Metall. Mater. Trans. A, 42 (2011), 3680.

6) F. Humphreys and M. Hatherly: Recrystallization and Related Annealing Phenomena, Elsevier Science \& Technology, Oxford, (2004), 1 .

7) P. R. Rios, F. Siciliano, Jr., H. R. Z. Sandim, R. L. Plaut and A. F. Padilha: Mater. Res., 8 (2005), 225.

8) R. D. Doherty, D. A. Hughes, F. J. Humphreys, J. J. Jonas, D. J. Jensen, M. E. Kassner, W. E. King, T. R. McNelley, H. J. McQueen and A. D. Rollett: Mater. Sci. Eng. A, 238 (1997), 219.

9) E. P. Abrahamson, II and B. S. Blakeney, Jr.: Trans. AIME, 218 (1960), 1101.

10) C. Antonione, G. Della Gatta, A. Lucci, G. Riontino and G. Venturello: Acta Metall., 18 (1970), 1169.

11) S. F. Medina and J. E. Mancilla: ISIJ Int., 36 (1996), 1063.

12) M. Suehiro: ISIJ Int., 38 (1998), 547.

13) J. Drumond, O. Girina, J. F. da Silva Filho, N. Fonstein and C. A. S. de Oliveira: Metallogr. Microstruct. Anal., 1 (2012), 217.

14) D. Z. Yang, E. L. Brown, D. K. Matlock and G. Krauss: Metall. Trans. A, 16 (1985), 1385.

15) T. Ogawa: Int. J. Mech. Mater. Eng., 10 (2015), 10

16) G. Liu, J. Li, S. Zhang, J. Wang and Q. Meng: J. Alloy. Compd., 666 (2016), 309.

17) T. F. Majka, D. K. Matlock and G. Krauss: Metall. Mater. Trans. A, 33 (2002), 1627.

18) M. Krugla, S. E. Offerman, J. Sietsma, P. Seda and D. N. Hanlon: Proc. Int. Symp. on New Developments in Advanced High Strength Sheet Steels, ed. by E. de Moor, AIST, Warrendale, PA, (2017).

19) H. Guo, G. R. Purdy, M. Enomoto and H. I. Aaronson: Metall. Mater. Trans. A, 37 (2006), 1721

20) H. Guo and M. Enomoto: Metall. Mater. Trans. A, 38 (2007), 1152.
21) J. W. Cahn: Acta Metall., 10 (1962), 907.

22) M. Hillert and B. O. Sundman: Acta Metall., 24 (1976), 731.

23) C. Qiu, H. S. Zurob, D. Panahi, Y. J. M. Brechet, G. R. Purdy and C. R. Hutchinson: Metall. Mater. Trans. A, 44 (2013), 3472.

24) C. Qiu, H. S. Zurob and C. R. Hutchinson: Acta Mater., 100 (2015), 333.

25) M. Enomoto: Acta Mater., 47 (1999), 3533.

26) H. P. Van Landeghem, B. Langelier, D. Panahi, G. R. Purdy, C. R. Hutchinson, G. A. Botton and H. S. Zurob: JOM, 68 (2016), 1329.

27) V. Massardier, J. Merlin, E. Le Patezour and M. Soler: Metall. Mater. Trans. A, 36 (2005), 1745

28) Y. Tanaka, S. Takaki, T. Tsuchiyama and R. Uemori: ISIJ Int., 58 (2018), 1927.

29) T. Rout, J. Go, A. Gaikwad and S. Melzer: Mater. Sci. Forum, 696 (2011), 107.

30) S. Melzer and J. Moerman: Microstructure and Texture in Steels and Other Materials, ed. by A. Haldar, S. Suwas and D. Bhattacharjee, Springer, London, (2009), 267.

31) S. Zaefferer and N. N. Elhami: Acta Mater., 75 (2014), 20.

32) D. Joy: Curr. Opin. Solid State Mater. Sci., 2 (1997), 465.

33) Y. Lü, D. A. Molodov and G. Gottstein: Acta Mater., 59 (2011), 3229.

34) F. J. Humphreys: Mater. Sci. Forum, 467-470 (2004), 107.

35) J. Farjas and P. Roura: Acta Mater., 54 (2006), 5573.

36) K. Nakashima, M. Suzuki, Y. Futamura, T. Tsuchiyma and S. Takaki: Mater. Sci. Forum, 503-504 (2006), 627.

37) T. Shintani and Y. Murata: Acta Mater., 59 (2011), 4314.

38) L. Bäcke: ISIJ Int., 50 (2010), 239.

39) H. S. Zurob, D. Panahi, C. R. Hutchinson, Y. Brechet and G. R. Purdy: Metall. Mater. Trans. A, 44 (2013), 3456.

40) D. A. Porter and K. E. Easterling: Phase Transformations in Metals and Alloys, Chapman and Hall, London, (1992), 1.

41) D. Malakhov and M. Tokuda: Mater. Trans., JIM, 36 (1995), 757.

42) Z. Ma: Metall. Mater. Trans. B, 32 (2001), 87.

$43)$ Z. Q. Lv, S. H. Sun, Z. H. Wang, M. G. Qv, P. Jiang and W. T. Fu: Mater. Sci. Eng. A, 489 (2008), 107.

44) N. Peranio, F. Roters and D. Raabe: Mater. Sci. Forum, 715-716 (2012), 13.

45) J. Andersson, T. Helander, L. Hoglund, P. Shi and B. Sundman: Calphad, 26 (2002), 273

46) M. Enomoto, C. L. White and H. I. Aaronson: Metall. Trans. A, 19 (1988), 1807.

47) B. Krakauer and D. Seidman: Phys. Rev. B, 48 (1993), 6724

48) P. Lejček and S. Hofmann: Interface Sci., 1 (1993), 163.

49) H. Oikawa: Technol. Rep. Tohoku Univ., 48 (1983), 1.

\section{Appendices}

\section{A. Zener Pinning}

The Zener pinning pressure can be described by this equation,

$$
P_{z}=\frac{3 F_{v} \gamma_{b}}{d}
$$

where, $F_{v}$ is the volume fraction of the particles, $\gamma_{b}$ is the grain boundary energy of the precipitate boundary, $d$ is the size of the precipitates.

In case of cementite, the Zener pinning is calculated to be in the range of $0.2 \mathrm{MPa}$, with input parameters as follow: $F_{v}=3$ vol $\%, \gamma_{b} \cong 0.5 \mathrm{~J} / \mathrm{m}^{2}, d=0.2 \mu \mathrm{m}$ (from Fig. 7). Even when we consider only pearlitic region, with $F_{v}=8$ vol\%, the Zenner pinning amounts to 0.6 $\mathrm{MPa}$. Since we observe almost no cementite in the ferritic regions, the Zener pinning pressure will be zero there. In case of MnS precipitates, the volume fraction is even lower than cementite. They are most commonly observed within pearlitic regions. Since in our experimental materials we did not modify them, they solidified as eutectic and after processing appear elongated. Using following input parameters $-F_{v}=0.02 \mathrm{vol} \%$ (see Table 1), $\gamma_{b} \cong 0.5 \mathrm{~J} / \mathrm{m}^{2}, d=0.5 \mu \mathrm{m}$ - the resulting Zener pinning is calculated to be in the range of $600 \mathrm{~Pa}$. Even with the assumption that all $\mathrm{MnS}$ are in the ferritic region we arrive at Zener pinning value of $900 \mathrm{~Pa}$, which is insignificant when compared to other contributors. 